interpretada como um balanço de partículas no espaço de fases.

Outro fato a destacar é que de maneira análoga que a fluidodinâmica dos meios contínuos é uma conseqüência direta da mecânica estatística, a introdução da chamada Lei de Fick, que correlaciona a corrente de nêutrons com um gradiente de fluxo, i.e. $\quad \mathbf{J}=-D \nabla \Phi$, reduz a equação de transporte a um "modelo do continuo" para nêutrons, denominada teoria da difusão.
Desta forma, indiretamente, L. Boltzmann, é de certa forma o "pai" da física dos reatores nucleares, e mesmo na sua época sem o conhecimento das reações nucleares, e da mecânica quântica, será a sua equação a base para o projeto dos reatores nucleares atuais, e a nossa comunidade de física de reatores tem este brilhante cientista como o pilar de seu trabalho.

José Rubens Maiorino E-mail: maiorino@ipen.br

\title{
Sobre os potenciais de condutores em movimento
}

Publicamos em 2001 artigo nesta Revista [1], intitulado 'Esfera condutora em movimento: campo, potenciais e dúvidas'. As 'dúvidas' se referiam ao sentido físico do potencial escalar da esfera carregada em movimento e, principalmente, ao do potencial vetor que devemos atribuir à mesma. Com referência à Fig. 1, reproduzida daquele artigo, os principais pontos a recordar são os seguintes:

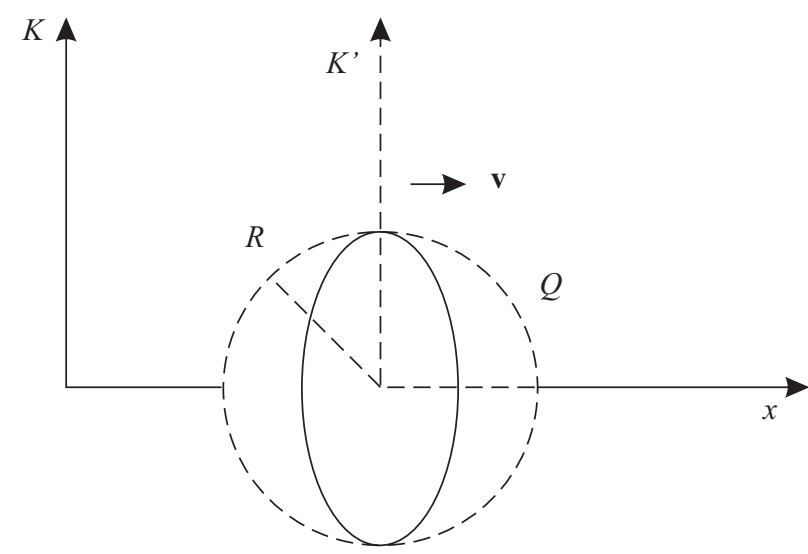

Figura 2 - Esfera no sistema $K^{\prime}$, em tracejado, vista do sistema $K$, traço cheio.

1) Para um observador no sistema $K$, a 'esfera' é um elipsóide achatado na direção de movimento e de revolução nas outras duas.

2) O potencial escalar do condutor em movimento, $\Phi$ em $K$, é maior do que o mesmo em $K^{\prime}, \Phi^{\prime}$, este igual a $Q / R$, pelo fator $\gamma=\left(1-v^{2} / c^{2}\right)^{-1 / 2}$, ou seja $\Phi=\gamma \Phi^{\prime}$. Os símbolos têm o sentido habitual, $Q$, carga, $R$, raio, $v$, velocidade da esfera e $c$, velocidade da luz.

3) Além do potencial escalar $\Phi$, devemos atribuir à 'esfera' condutora em movimento um potencial vetor, com uma componente exclusivamente na direção de movimento $A_{x}=v \Phi / c$

4) No sistema $K$, a normal ao condutor está na direção do 'campo' de Lorentz local, $\mathbf{E}+\mathbf{v} \times \mathbf{B} / c$.

5) O aumento do potencial escalar em $K$ deve ser atribuído ao fato de que nele os potenciais efetivos são os de Liénard-Wiechert, que, lembramos, não são simplesmente retardados pois incluem o fator de "paralaxe cinética', $(1-\mathbf{v} \cdot \hat{\mathbf{r}} / c)^{-1}$, sendo $\hat{r}$ o vetor unitário de $\mathbf{r}$ ao ponto considerado [2].

Gostaríamos de fazer aqui os seguintes esclarecimentos em relação ao trabalho anterior:

I) Os potenciais que o observador em $K$ atribui são sistêmicos, isto é, ao condutor em movimento como um todo. Notemos que o potencial escalar $\Phi$ é maior que $\Phi^{\prime}$, este medido em $K^{\prime}$, pelo fator $\gamma$, ou seja, na mesma proporção em que a massa relativística aumenta ao se passar de $K$ ' a $K$. Se adotamos o ponto de vista de que massa e energia são equivalentes, o aumento da energia potencial representa o aumento da 'energia elétrica' (ver ítem a seguir) do condutor em movimento.

II) Para nossa surpresa, se calcularmos as integrais dos quadrados dos campo elétrico e magnético no exterior do elipsóide, a grandeza obtida não parece guardar nenhuma relação direta com $\Phi$ [4]. Por esta razão, chamamos este, ou seu produto com $Q$, de 'energia elétrica', ligado ao conceito de potencial eletrostático ao qual os elétrons metálicos seriam sensíveis, imóveis ou móveis.

III) Tendo em conta o resultado mencionado no ítem 4) acima, concluimos que as transformações de Lorentz permitem encontrar a forma do condutor em movimento no qual a normal ao mesmo está na direção da força de Lorentz em cada ponto de sua superfície.

IV) A dúvida principal deixada no artigo se referia à interpretação a ser dada ao potencial vetor do condutor em movimento, igual a $v \Phi / c$ na direção de movimento. As considerações feitas no item I) sugerem que ele represente a quantidade de movimento associado à 
energia elétrica, necessariamente unida à energia numa entidade única 'energia-momento', como um quadrivetor da relatividade ou um multivetor 0-1 da álgebra geométrica, ou de Clifford.

V) Sabemos que se a esfera é supercondutora, seus pares bosônicos são sensíveis ao potencial vetor, de tal maneira que - na linguagem de Feynman [3] - o $p$ momento, igual à soma do $m v$-momento e ao produto da carga pelo potencial vetor (ou momento elétrico, na nossa), é conservado. Se imaginamos que ela, inicialmente parada, recebe impulsivamente a velocidade $v$ no sistema $K$, temos que o $p$-momento, inicialmente nulo, assim permanece porque para cada elétron no interior do condutor, vale a relação $m v+q A_{x}=0$ (pois $q$, carga do elétron, é negativa) de acordo com a argumentação desenvolvida em IV.

G.F. Leal Ferreira

DFCM, IF - São Carlos, E-mail: guilherm@if.sc.usp.br

\section{Referências}

[1] G.F. Leal Ferrreira, Rev. Bras. Ens. Fis. 23, 141 (2001).

[2] R.P. Feynman, R.B. Leighton e M. Sands, The Feynman Lectures on Physics, $v$.2 (Addison Wesley, Reading, 1965).

[3] V. 3 da Ref. [2].

[4] Obtivemos para $(1 / 8 \pi) \int_{0}^{\pi} 2 \pi \operatorname{sen} \theta d \theta \int_{r(\theta)}^{\infty}\left(E^{2}+\right.$ $\left.B^{2}\right) r^{2} d r$ o resultado $Q^{2}\left(3-v^{2} / c^{2}\right) /\left(6 R \sqrt{1-v^{2} / c^{2}}\right)$. 